\title{
Alcohol and prescription drug safety in older adults
}

This article was published in the following Dove Press journal:

Drug, Healthcare and Patient Safety

23 February 2013

Number of times this article has been viewed

\author{
Faika Zanjani ${ }^{1,2}$ \\ Aasha I Hoogland' \\ Brian G Downer' \\ 'Department of Gerontology, \\ ${ }^{2}$ Building Interdisciplinary Research \\ Careers in Women's Health University \\ of Kentucky, Lexington, KY, USA
}

Background: The objectives of this study were to investigate older adults' knowledge of prescription drug safety and interactions with alcohol, and to identify pharmacists' willingness to disseminate prescription drug safety information to older adults.

Methods: The convenience sample consisted of 48 older adults aged 54-89 years who were recruited from a local pharmacy and who completed surveys addressing their alcohol consumption, understanding of alcohol and prescription drug interactions, and willingness to change habits regarding alcohol consumption and prescription drugs. To address pharmacist willingness, 90 pharmacists from local pharmacies volunteered and answered questions regarding their willingness to convey prescription drug safety information to older adults.

Results: Older adults reported low knowledge of alcohol and prescription drug safety, with women tending to be slightly more knowledgeable. More importantly, those who drank in the previous few months were less willing to talk to family and friends about how alcohol can have harmful interactions with prescription drugs, or to be an advocate for safe alcohol and prescription drug use than those who had not had a drink recently. Pharmacists reported that they were willing to convey prescription drug safety information to older adults via a variety of formats, including displaying or distributing a flyer, and directly administering a brief intervention.

Conclusion: In this study, older adults were found to have inadequate knowledge of prescription drug safety and interactions with alcohol, but pharmacists who regularly come in contact with older adults indicated that they were ready and willing to talk to older adults about prescription drug safety. Future research should focus on interventions whereby pharmacists disseminate prescription drug safety information to older adults in order to improve healthy prescription drug and alcohol behavior and reduce medical and health costs associated with interactions between alcohol and prescription drugs.

Keywords: aging, alcohol, drug, pharmacist, prescription drugs, safety

\section{Introduction}

There is considerable evidence that pharmacists consider alcohol to be a dangerous substance when combined with certain prescription drugs, ${ }^{1}$ and research has shown that alcohol can interact with prescription medications by altering the availability of the drug, increasing drug toxicity, and magnifying the inhibitory effects of alcohol. ${ }^{2-4}$ Adverse interactions between alcohol and prescription drugs have been seen with anesthetics, antibiotics, anticoagulants, antidepressants, antidiabetics, antihistamines, antipsychotics, anticonvulsants, antiulcer agents, cardiovascular agents, narcotic and non-narcotic pain relievers, and sedatives/hypnotics. ${ }^{5,6} \mathrm{~A}$ recent report on prescription drug and alcohol interactions among primary care patients with alcohol use disorders
Correspondence: Faika Zanjani

Department of Gerontology,

University of Kentucky, 740 South

Limestone, J525 Kentucky Clinic

Lexington, KY 40536, USA

Tel +l 8592180195

$\mathrm{Fax}+\mathrm{I} 8593235747$

Email f.zanjani@uky.edu
Drug, Healthcare and Patient Safety 2013:5 I3-27

(C) 2013 Zanjani et al, publisher and licensee Dove Medical Press Ltd. This is an Open Access article

Dovepress

http://dx.doi.org/1 0.21 47//DHPS.S38666 which permits unrestricted noncommercial use, provided the original work is properly cited. 
indicated that $40 \%$ of adults were taking medications which interact with alcohol, and $20 \%$ of patients were taking medications with moderate to severe alcohol interactions. Further, over one third of these patients did not recall advice to avoid alcohol. ${ }^{7}$

In older adults, alcohol use is fairly common, and it has been estimated that over one half of community-residing older adults consume alcohol, and $25 \%$ consume more than a single drink a day. ${ }^{8}$ Of particular concern are the hazards of interactions between alcohol and prescription drugs in older adults, who are a high-risk group for these interactions, ${ }^{9,10}$ largely due to their aging physiology ${ }^{11}$ (eg, drug metabolism, cognitive decline) and their high rate of prescription drug consumption. ${ }^{2,12}$ Approximately $77 \%$ of older adults take one alcohol-interactive medication, and 20\% take alcoholinteractive medications and also consume alcohol. ${ }^{13}$ While the literature to date has not adequately assessed the actual prevalence of interactions between alcohol and prescription drugs in older adults, the research indicates that alcohol can interfere with the ability to follow instructions for prescription use, ${ }^{14}$ and lead to as many hospitalizations as for myocardial infarction in the elderly. ${ }^{15}$ Importantly, drinking rates are expected to increase for future generations, ${ }^{16}$ which could potentially lead to even higher rates of alcohol consumption while taking alcohol-interactive medications.

The literature indicates that prescription drug use is very common in older adults, with approximately $60 \%$ of adults over 60 years of age using prescription drugs, and roughly $90 \%$ of adults taking prescription drugs by the age of 80 years. ${ }^{17}$ Prescription drug safety is likely to become more of an issue in the future with the aging of baby boomers, due to reports of heavier drinking in this age group compared with earlier cohorts. ${ }^{14}$ However, prescription drug safety is a largely underrecognized and undermanaged health issue. There has been extensive research examining the effects of physician-delivered alcohol interventions, but success appears hampered by limited patient access. ${ }^{18,19}$ Interventions to improve prescription drug safety and alcohol intake among older adults in pharmacy settings are rare, despite high accessibility and regular patient contact, ${ }^{20}$ expertise in medication interactions, ${ }^{21}$ and a mission to reduce medication interactions. ${ }^{22}$ Yet there is evidence for pharmacist-based interventions improving health. Specifically, success has been reported with pharmacist-based interventions for medication adherence, ${ }^{23}$ medication misuse, ${ }^{24}$ medication disposal, ${ }^{25}$ diabetes management, ${ }^{26}$ stroke prevention, ${ }^{27}$ blood pressure control, ${ }^{28}$ vaccinations, ${ }^{11}$ and disease management. ${ }^{29}$ Further, pharmacy settings have a well-known community presence, and a major role in medication adherence, drug interaction/ adversity education, and medication issues. ${ }^{30}$ Also, as evidenced by the aforementioned community interventions, pharmacists/pharmacies are considered to be integrated community components that can promote change. ${ }^{31}$ Accordingly, pharmacies can be vital settings for creating health change within rural communities with barriers to clinical access. However, while there has been recognition in the US of the need for alcohol screening when prescribing alcoholinteractive medications ${ }^{32}$ and for pharmacists to provide information on the safety of prescription drugs, ${ }^{33-35}$ work in this area has been limited to acknowledgment only.

Currently, little is known about pharmacists' willingness to deliver prescription drug and alcohol safety information to patients, but there is evidence indicating that older adults are eager to learn about safe alcohol use even when they are not prompted to do so, and find it to be a relevant topic for their age group. ${ }^{36}$ If information could be disseminated to patients through pharmacies, then pharmacists could likely help to decrease the frequency of interactions between prescription drugs and alcohol in older adults. To date, the literature does not adequately address this possibility. As such, the objectives of this study were to determine the extent of older adults' drinking habits and knowledge of prescription drug safety, compare older adults' drinking habits and knowledge of prescription drug safety across genders, and assess the degree to which pharmacists are willing to relate relevant prescription drug safety information to older customers. Gender was selected as a key demographic variable to examine because of known gender differences in age-related health outcomes and health behaviors, such as alcohol consumption. ${ }^{37}$

\section{Materials and methods Determining older adults' knowledge of prescription drug safety}

Older patrons at a local pharmacy in Lexington, KY, were recruited to participate in a survey on prescription drug safety during the summer of 2011. One pharmacy was used to assess feasibility and analyze preliminary data; a research assistant set up a recruitment table in this pharmacy. After explaining the study, participants were asked to complete the consent form and a pencil and paper survey in return for a $\$ 5$ gift card to be used at that particular pharmacy. The $\$ 5$ amount was calculated considering the time required to complete the survey, using a $\$ 10$ per hour rate for study participants. Surveys included sections on demographics, alcohol usage, and prescription drug safety. Participants were informed to expect the survey to take 20 minutes to complete; the actual 
amount of time it took for participants to complete the survey ranged from ten to 30 minutes. Adults who did not speak English were not eligible for participation (bilingual participants were eligible, however) because the survey was only made available in English. Participants were allowed to complete the survey either at the pharmacy or at their home. In order to limit potential response bias, participants who completed the survey at the pharmacy were informed about a designated partitioned booth away from the researcher for additional privacy and security.

The prescription drug safety survey consisted of 21 substantive prescription drug safety questions, a one-page demographic section, and a four-question alcohol assessment; the survey was created specifically for this study, ensuring face validity (Supplementary materials). The instrument itself was designed to address barriers to health promotion ${ }^{38}$ in consultation with a pharmacist with expertise in geriatrics. The demographic section of the survey assessed age, gender, race, county, marital status, living situation, employment status, education, and income. Alcohol usage was determined by asking participants to record how many drinks they had consumed each day during the previous week, and the number of times they had consumed 3-5 drinks at once during the previous 3 months (adapted from a previous assessment ${ }^{39}$ ). Prescription drug safety was assessed by five sets of questions addressing: beliefs, behavior, knowledge, literacy, and motivation. The belief component contained seven Likert response questions (rated on a five-point scale from very true to very false) presenting statements applicable to prescription drug safety and alcohol interactions. The behavioral component comprised two questions pertaining to personal experiences with alcohol and prescription drug interactions (yes/no response) and whether participants inquired about interactions between alcohol and prescription drugs with their pharmacist (rated on a five-point Likert scale from always to never). The knowledge section included four questions addressing each participant's understanding of how alcohol and prescription medications can interact with one another. Question formats for the knowledge section included a Likert scale (rated on a five-point scale from always to never) for one question, and multiple choices for the subsequent three questions. Literacy questions (adapted from a prior assessment ${ }^{40}$ ) addressed whether participants needed assistance with materials distributed by their pharmacy, and their overall understanding of their own medications and potential side effects. Four questions were used to assess literacy, with formats including one using a Likert scale (rated on a five-point scale from never to always), and the remaining three with yes/no responses. The motivation section assessed willingness to change personal habits and/or talk to others about interactions between alcohol and prescription drugs. In the motivation section, participants were instructed to respond to four questions on a Likert scale (rated on a five-point Likert scale from always to never). The alcohol and literacy questions were adapted from existing instruments.

\section{Determining willingness of pharmacists to provide information}

Surveys were disseminated through the University of Kentucky's College of Pharmacy via fax to American Pharmacy Services Corporation pharmacies $(n=191)$ and Kroger grocery stores with pharmacies in Kentucky $(\mathrm{n}=103)$. American Pharmacy Services Corporation pharmacies were selected because of their involvement with independent communities. A letter explaining the content, purpose, and confidentiality of the survey was attached and sent with each survey. Further, a notification was sent out to each pharmacy 3 days before distribution of the survey to provide advanced notice. Reminder notices were sent out one week after distribution of the survey, and all surveys were collected between February 10 and 24, 2010. More information about the survey can be found in earlier publications. ${ }^{41,42}$

The survey was initially created by American Pharmacy Services Corporation and individuals at the University of Kentucky's College of Pharmacy, and amended to address the aims of the current study. Demographic information asked for each pharmacist's age, gender, pharmacy degree, and number of years spent practicing in the community. Information was collected pertaining directly to the pharmacy each participant worked in, including number of prescriptions filled and hours worked per week and whether the pharmacy was in an urban or rural area. Amended questions addressed each pharmacist's interest in disseminating prescription drug safety information to older adults.

\section{Data analysis}

All data were analyzed descriptively and inferentially for each item using SAS version 9.3 (Cary, NC). Gender was chosen as an independent variable in order to identify any potential differences in alcohol consumption or prescription drug safety knowledge between men and women. Tests involving continuous dependent variables (ie, age, number of drinks consumed, and Likert scale responses that reflected nonqualitative shifts for each possible response) were analyzed using independent-samples $t$-tests with gender as the independent variable, and tests with discrete variables 
(ie, gender, yes/no responses, what is a safe amount of alcohol to consume with prescription medication) were analyzed using Chi-square tests with gender as the independent variable. Alpha was set at 0.05 .

\section{Results \\ Older adults' knowledge of prescription drug safety \\ Participants}

A total of 48 older adults (mean age $71.68 \pm 7.7$ years), the majority of whom resided in Lexington, KY, completed the survey packets. The participant sample consisted of nonHispanic whites (93.8\%) who were highly educated and of mean age $16.89 \pm 3.02$ years, and reported a relatively high annual income (mean USD 64,212.77 $\pm 84,239.81$ ). In addition, most participants were married (62.5\%), retired (75.0\%), and lived either alone or with a spouse $(81.2 \%)$. No gender differences were found for age, marital status, living situation, employment status, education, or income (all $P>0.1$ ). Eight participants did not indicate their gender, and thus were excluded from analyses comparing responses by gender.

\section{Beliefs}

Participants reported high levels of belief for all statements except for "unexpected symptoms can be dangerous," "alcohol consumption at any level can be harmful," and "it is important to consume no more than one drink per day" (see Table 1). Marginal and significant gender differences were found, with females tending to exhibit higher levels of belief than males for responses to the latter two statements only ( $P=0.10$ and $P=0.04$, respectively).

\section{Behavior}

The vast majority of participants (96\%) reported never having experienced an alcohol and prescription drug interaction (see Table 1). Only one-fifth of participants indicated that they always or almost always talked with their doctor or pharmacist about how alcohol can interact with their prescriptions. No gender differences were found for either question.

\section{Knowledge}

Participants reported varied knowledge of interactions between alcohol and prescription medications (see Table 1). When asked whether medications and alcohol can always be used safely together, only two participants felt that this was always or almost always true, and females were less likely than males to agree with the statement $(P=0.02)$.
Only one-third of participants reported that no amount of alcohol was safe to consume with medication, and another third of participants felt that one or fewer drinks per day was a safe amount. When choosing specific medications, most participants were aware that consuming alcohol can be dangerous when taking prescription medications for pain or psychiatric conditions, but fewer than half selected Tylenol ${ }^{\circledR}$ or Advil ${ }^{\circledR}$ as being dangerous as well (see Table 1). No significant gender differences were found.

With regards to specific harmful interactions between prescription drugs and alcohol, the most commonly indicated were driving impairment, falling, memory loss, and drowsiness (see Table 1). Across genders, fewer than half of the participants recognized that interactions between prescription drugs and alcohol can result in infection, disease, hospitalization, disability, or mental decline. Women generally identified more interactions between prescription drugs and alcohol than males $(P=0.03)$, and most gender differences indicated that women had better knowledge of prescription drug safety.

\section{Literacy}

The majority of participants (87\%) required help with reading instructions, pamphlets, or related written materials from their doctor or pharmacy (see Table 1). About half of the participants knew a specific drug interaction for a medication they were taking, or could list which medications they were taking that should not be taken with alcohol. Approximately two-thirds of participants could list at least one side effect for each medication they were taking. No gender differences were found across questions.

\section{Motivation}

Slightly more than half of the participants stated they were always willing to talk with their doctor, with men indicating more willingness than women $(P=0.07)$. Approximately half of the participants stated that they were willing to change their alcohol consumption habits to prevent harmful interactions with prescription drugs, talk to friends/family about interactions between prescription drugs and alcohol, and advocate for safe use of alcohol and prescription drugs (see Table 1). No gender differences were found for these latter three questions.

\section{Alcohol}

Approximately two-thirds of the sample reported having consumed alcohol in the previous 3 months, and participants reported an average alcohol intake of $0.86 \pm 1.17$ drinks 


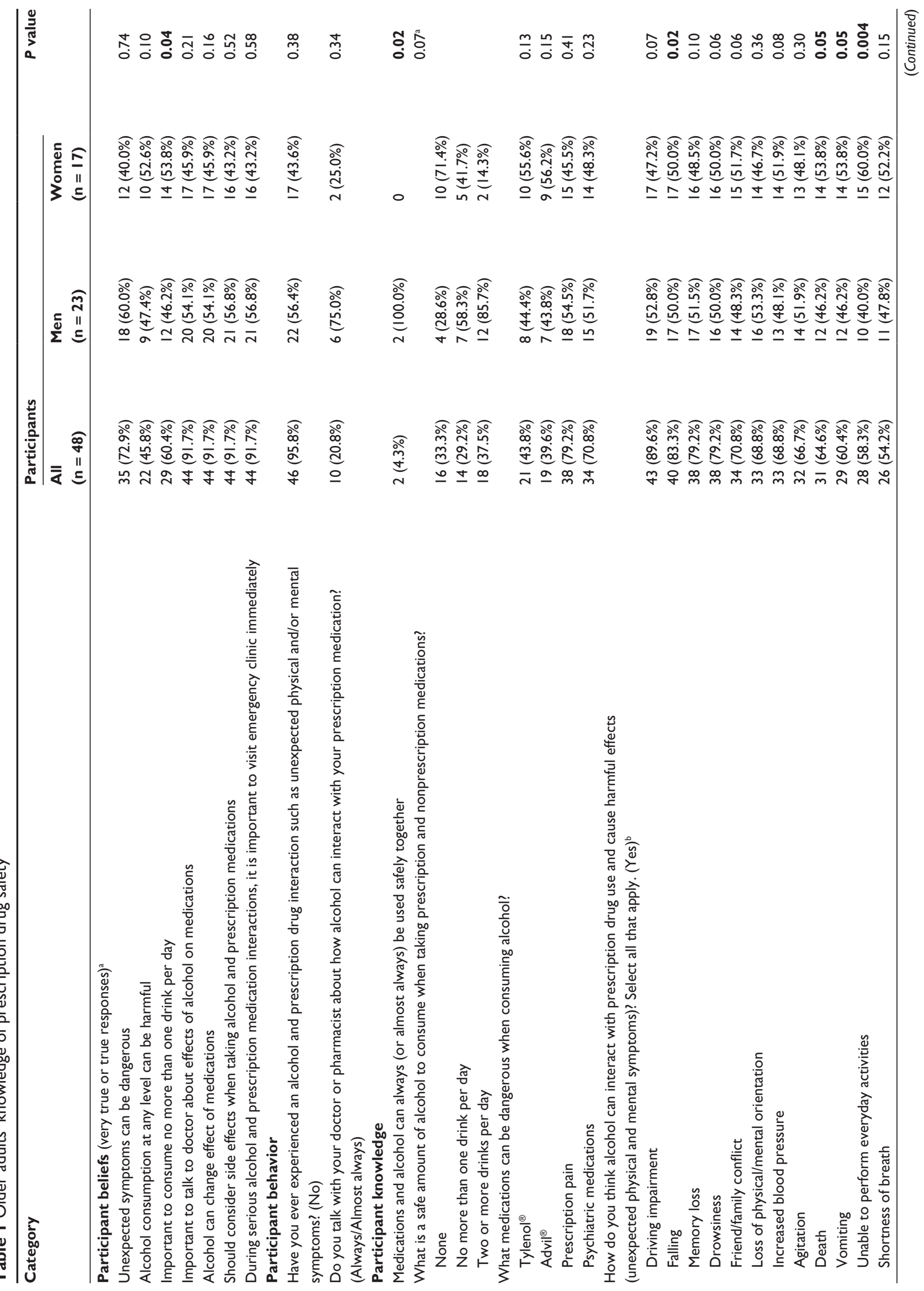




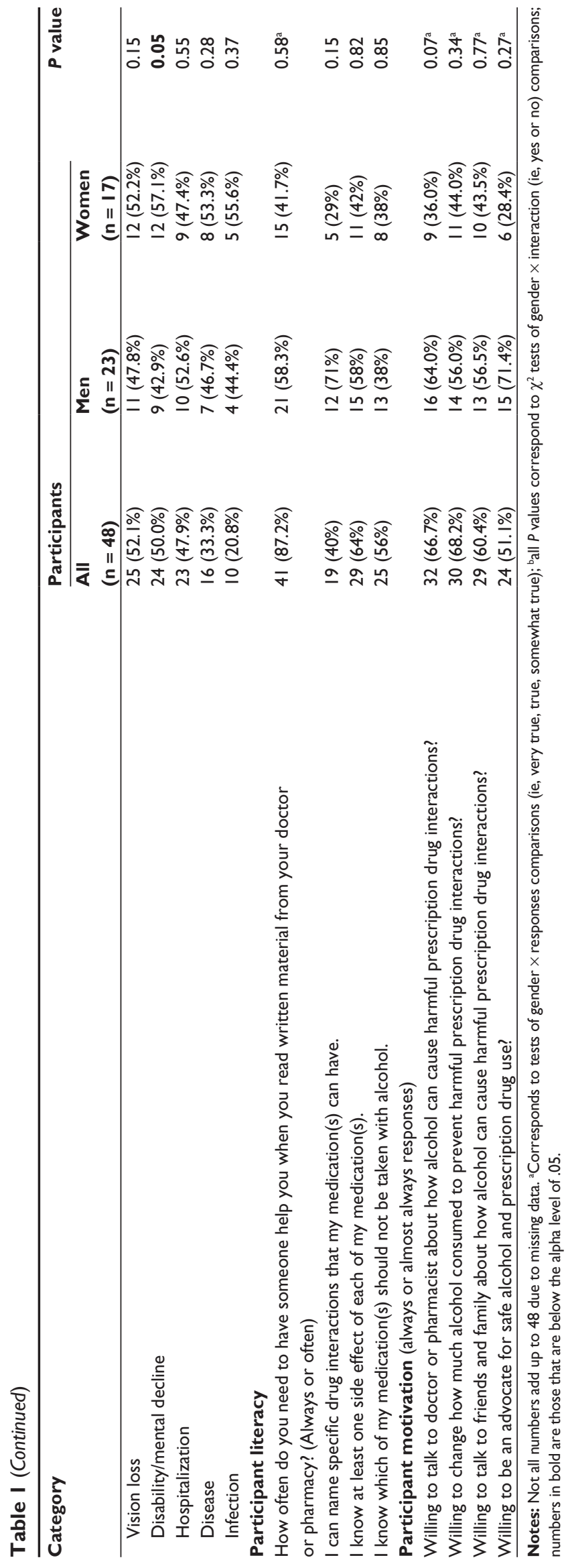

per day, which was not found to differ by gender $(t(32)=1.24$, $P=0.23$ ). Heavy alcohol use, defined as drinking more than three drinks a day, and binge drinking, defined as drinking up to 4-5 drinks a day (or 4 if over 64 years of age), was also not found to differ by gender (see Table 2). Approximately $11 \%$ of the sample reported binge drinking and $15 \%$ reported heavy drinking.

Participants who consumed alcohol in the previous 3 months named fewer interactions between prescription drugs and alcohol than those who had not had a drink in the same time frame, regardless of gender $(t(46)=-2.4, P=0.02)$. Similarly, participants who had had a drink in the previous 3 months tended to name fewer medications with bad consequences than those who had not had a drink in the same time frame $(t(46)=-1.67, P=0.10)$. In addition, participants who had had a drink in the previous 3 months were less willing to talk to family and friends about how alcohol can cause harmful prescription drug interactions $(t(46)=2.34 ; P=0.02)$, or to be an advocate for safe alcohol and prescription drug use $(t(45)=2.08, P=0.04)$. No other alcohol effects were found across prescription drug safety responses.

\section{Willingness of pharmacists to provide information}

Participants

Eligible participants included independent owners, pharmacists in charge, and staff pharmacists, with no exclusion criteria. Survey data were supplied by 25 participants from Kroger stores and 65 participants from American Pharmacy Services Corporation pharmacies, yielding a total of 90 participants (see Table 3). More rural pharmacists participated than urban pharmacists, and most participants were men with over 20 years of experience in dispensing medication. Rural pharmacists tended to be older than the urban pharmacists, but no significant differences were found for gender or number of years practicing pharmacy. Conversely, urban pharmacies tended to fill more prescriptions than rural pharmacies, and stayed open significantly longer than rural pharmacies (see Table 3).

\section{Willingness to disseminate information}

Most pharmacists were willing to work with older adults on research to improve prescription drug safety, and to raise awareness regarding alcohol consumption and prescription drug safety. Importantly, at least three quarters of pharmacists reported that they would be willing to display or distribute a flyer to patients in order to promote prescription drug safety (see Table 3). 
Table 2 Older adults' self-reported alcohol use

\begin{tabular}{|c|c|c|c|c|}
\hline \multirow[t]{2}{*}{ Question } & \multicolumn{3}{|c|}{ Participants } & \multirow[t]{2}{*}{$P$ value } \\
\hline & $\begin{array}{l}\text { All } \\
(n=48)\end{array}$ & $\begin{array}{l}\text { Men } \\
(n=23)\end{array}$ & $\begin{array}{l}\text { Women } \\
(n=17)\end{array}$ & \\
\hline Total (mean) alcohol consumed in last week? $( \pm \mathrm{SD})$ & $0.86(1.17)$ & $\mathrm{I} .03(0.3 \mathrm{I})$ & $0.50(0.92)$ & 0.23 \\
\hline Drank alcohol in the past 3 months? & & & & 0.68 \\
\hline Yes & $32(66.7 \%)$ & $15(60.0 \%)$ & $10(40.0 \%)$ & \\
\hline No & $16(33.3 \%)$ & $8(53.3 \%)$ & $7(46.7 \%)$ & \\
\hline How many times had 5 or more drinks in a single day & & & & 0.11 \\
\hline \multicolumn{5}{|c|}{ ( 4 or more if over 64 years or female) during past 3 months? } \\
\hline None & $42(89.4 \%)$ & $18(51.4 \%)$ & $17(48.6 \%)$ & \\
\hline 1 & 0 & 0 & 0 & \\
\hline 2 or more & $5(10.6 \%)$ & $4(100.0 \%)$ & 0 & \\
\hline How many times had 3 or more drinks in a single day & & & & 0.64 \\
\hline \multicolumn{5}{|l|}{ during past 3 months? } \\
\hline None & $35(74.5 \%)$ & $16(55.2 \%)$ & $13(44.8 \%)$ & \\
\hline 1 & $3(6.38 \%)$ & I (50.0\%) & I (50.0\%) & \\
\hline 2 & $2(4.26 \%)$ & 0 & $2(100.0 \%)$ & \\
\hline 6 or more & 7 (I4.9\%) & 5 (83.3\%) & I (I6.7\%) & \\
\hline
\end{tabular}

Note: Not all numbers add up to 48 due to missing data.

Abbreviation: SD, standard deviation.

Most pharmacists also reported a willingness to screen patients, although rural pharmacists were much more willing to carry out patient screenings than urban pharmacists $(t(88)=-3.30, P=0.001)$. Similarly, most pharmacists were willing to refer a patient to an intervention program if necessary, but rural pharmacists tended to report a higher willingness to do so than urban pharmacists $(t(88)=-1.66$,
$P=0.10)$. Fewer than half of participants were willing to host a kiosk or deliver a 10-minute (or less) intervention, but most were willing to deliver a 1-5-minute intervention. Interestingly, urban pharmacists appeared to be more willing to deliver a one-minute intervention than a 5-minute intervention, while rural pharmacists displayed the reverse pattern. Further, significantly more rural pharmacists than urban

Table 3 Characteristics of pharmacist ( $n=90,7 \%$ sampling, $31 \%$ response rate)

\begin{tabular}{|c|c|c|c|c|}
\hline & \multicolumn{3}{|c|}{ Pharmacists } & \multirow[t]{2}{*}{$P$ value } \\
\hline & $\begin{array}{l}\text { Total } \\
(n=90)\end{array}$ & $\begin{array}{l}\text { Urban } \\
(n=36)\end{array}$ & $\begin{array}{l}\text { Rural } \\
(n=54)\end{array}$ & \\
\hline \multicolumn{5}{|l|}{ Demographics } \\
\hline Mean age $( \pm S D)$ & $46.5(12.9)$ & $43.3(11.6)$ & $48.2(13.1)$ & 0.07 \\
\hline Gender (female) & $34(37.4 \%)$ & 14 (38.9\%) & $20(37.0 \%)$ & 0.86 \\
\hline Mean years practicing pharmacy $( \pm S D)$ & $22.2(14.0)$ & $19.3(12.0)$ & $23.7(14.7)$ & 0.14 \\
\hline Prescriptions filled in a typical week & 1464.9 & 1626.4 & 1331.8 & 0.09 \\
\hline Pharmacy hours open per week & 62.8 & 71.9 & 56.6 & $0.0007^{a}$ \\
\hline \multicolumn{5}{|l|}{ Intervention interests } \\
\hline Willing to work with older adults on research for improving PDS? & $95.6 \%$ & $91.7 \%$ & $98.2 \%$ & 0.14 \\
\hline Willing to raise awareness about alcohol consumption and PDS? & $91.1 \%$ & $86.1 \%$ & $94.4 \%$ & 0.17 \\
\hline \multicolumn{5}{|l|}{ Level of involvement to promote PDS } \\
\hline Display a flyer & $85.4 \%$ & $82.9 \%$ & $87.0 \%$ & 0.59 \\
\hline Distribute a flyer to patients & $81.1 \%$ & $75.0 \%$ & $85.2 \%$ & 0.23 \\
\hline Patient screening & $82.2 \%$ & $66.7 \%$ & $92.6 \%$ & $0.00 I^{b}$ \\
\hline Patient referral into intervention program & $73.3 \%$ & $63.9 \%$ & $79.6 \%$ & 0.10 \\
\hline Host a kiosk & $46.7 \%$ & $47.2 \%$ & $46.3 \%$ & 0.93 \\
\hline Directly deliver a $<$ one-minute intervention & $58.9 \%$ & $55.6 \%$ & $61.1 \%$ & 0.60 \\
\hline Directly deliver a $<5$-minute intervention & $63.3 \%$ & $50.0 \%$ & $72.2 \%$ & $0.03^{c}$ \\
\hline Directly deliver a $<10$-minute intervention & $37.8 \%$ & $22.2 \%$ & $48.2 \%$ & $0.0 I^{d}$ \\
\hline
\end{tabular}

Notes: aSignificant at the 0.3704 level when accounting for independent/chain store, with store type effect, $P<0.000$ I; ${ }^{b}$ significant at the 0.02 I 6 level when accounting for independent/chain store, but no store type effect; 'significant at the 0.1866 level when accounting for independent/chain store, but no store type effect; ${ }^{\mathrm{d}}$ significant at the 0.0464 level when accounting for independent/chain store, but no store type effect.

Abbreviations: PDS, prescription drug safety; SD, standard deviation. 
pharmacists said they were willing to deliver a 5-minute intervention to customers $(t(88)=-1.28, P=0.03)$. To ensure the rural/urban effects were not nested within independent/ chain effects, follow-ups were conducted, indicating that rural/urban effects were indeed valid with regard to level of involvement to promote prescription drug safety.

\section{Discussion}

The objectives of this study were to establish the level of prescription drug safety knowledge in older adults and assess pharmacy readiness to promote prescription drug safety in pharmacies. In the first part of the survey, patients indicated high levels of belief about the issues surrounding interactions between alcohol and prescription medication, with women tending to show a greater understanding. However, across genders, participants were not very aware that alcohol consumption at any level can be harmful, and that it is important to refrain from drinking more than one drink a day. These latter two findings suggest that while participants were mostly aware that alcohol and prescription medications can interact with undesired consequences, they were less aware of how even low levels of alcohol consumption can be harmful, and that they should monitor their personal levels of alcohol consumption.

The majority of participants drank alcohol, averaging almost a drink per day across genders, which is in accord with previous research. ${ }^{43,44}$ Regardless of drinking status, the participants appeared to be knowledgeable about the harmful effects of alcohol, but responses to most questions about safe alcohol and prescription drug use reveal that only half of the sample correctly identified harmful interactions between the two, making this domain a particular area of concern in our study. Further, our results indicate that women tended to have greater knowledge of prescription drug safety, but appeared to be less willing than men to talk to a doctor about interactions between alcohol and prescription medication. This gender difference contradicts prior literature that has found older women to be more likely to make healthy behavior changes than older men. ${ }^{41}$ Unfortunately, there is a dearth of literature addressing prescription drug safety, making it difficult to interpret the gender differences found in this study.

Of note, individuals who consumed alcohol were less knowledgeable about prescription drug safety, and less willing to talk to others about safe use of these substances. Considering that overall levels of prescription drug safety knowledge and practice in this sample of older adults was low, it is of particular concern that older adults who had consumed a drink in the recent past were even less knowledgeable about prescription drug safety, because they are at greater risk of experiencing harmful side effects as a result of interactions between alcohol and prescription drugs. ${ }^{7,8}$ Further, almost all participants reported having never experienced an alcohol and prescription drug interaction, but participants' low level of prescription drug safety knowledge and motivation to change prescription drug safety habits suggest that they might not know whether they have actually experienced an alcohol and prescription drug interaction. This notion is bolstered by the fact that half of participants did not even know a specific drug interaction for a drug they were taking and were not able to detail which of their medications should not be taken with alcohol. This finding is concerning, given that most older adults take at least one prescription medication that can interact with alcohol. ${ }^{11}$

In sum, our findings for the first part of this survey indicate that older adults do not have an adequate understanding of prescription drug safety and how alcohol can interact with prescription drugs, in particular, with regard to: beliefs, there was inadequate understanding that alcohol can be harmful; behavior, individuals were not consulting with doctor or pharmacist about alcohol and medication interactions; knowledge, inadequate knowledge about healthy alcohol consumption levels, over the counter medication and alcohol interactions, and harmful alcohol and prescription medication interaction outcomes; literacy, inadequate level of drug-interaction literacy; and motivation, moderate motivation to promote safe alcohol and prescription drug use. Most importantly, inadequate prescription drug safety was especially true for those who drink alcohol; about two thirds of the sample reported consuming alcohol, and were thus at an inherently higher risk of suffering interactions between alcohol and prescription drugs.

The second part of our survey revealed that pharmacists were willing to administer brief interventions to older adults in order to increase their knowledge about prescription drug safety. This finding is encouraging in light of research indicating pharmacists are concerned that older adults may react negatively in response to brief interventions. ${ }^{45}$ Brief pharmacist interventions would likely increase older adults' awareness of prescription drug safety, given that prescription warning labels are apparently not an effective means of warning older adults of the dangers of prescription drug and alcohol usage.

Alarmingly, research has shown that one third of older adults do not even look at prescription warning labels, and the remaining two thirds do not attend to the information as 
much as younger adults do. ${ }^{46}$ This pattern has the unfortunate consequence of reducing one's memory for the warning, particularly for older adults. However, when older adults do pay attention to the warning label, they tend to remember the information at a later point in time. As such, these findings suggest that increasing older adults' awareness of prescription drug safety will help them to retain that knowledge in the future.

Notably, pharmacists preferred a one-minute or 5-minute intervention to a 10-minute intervention, and research has indicated that brief interventions can be effective at reducing alcohol consumption. ${ }^{17}$ While such interventions appear to be more effective in men than in women, it should be noted that most participants reviewed have been men. Regardless, it is feasible that brief interventions with older adults explaining potential interactions between prescription drugs and alcohol might reduce alcohol consumption in men and potentially in women. Given that adults taking prescription medications tend to feel that pharmacists in particular are doing a good job at ensuring prescription drug safety, ${ }^{47}$ future studies assessing the benefits of pharmacist-based interventions promoting prescription drug safety are likely to yield encouraging results.

Another important finding from this study is that rural pharmacists in particular appear to be more willing to engage in in-depth consultations or screenings with patients than urban pharmacists. This result is particularly noteworthy, given that rural pharmacists reported being open for fewer hours and dispensing fewer medications than urban pharmacists. It is plausible that rural pharmacists feel a greater need to intervene with their clients given that they do not have as many opportunities to do so. Alternatively, it could be the case that urban pharmacists do not feel that they have the extra time to devote to educating clients about the dangers of alcohol and prescription drug use. However, given urban pharmacists' willingness to disseminate relevant prescription drug safety information to older adults, it is feasible that brief pharmacist-based interventions would be particularly effective in rural environments.

While this study adds to the existing literature by identifying prescription drug safety knowledge in older adults, there are a number of factors that limit the generalizability of our findings. Demographically, the sample was $93.8 \%$ white, with an average of 16.89 years of education, and an annual income of USD 64,000. These demographics differ from older adults in the US, who are approximately $80 \%$ white, ${ }^{48}$ fewer than half of whom have a bachelor's degree, ${ }^{49}$ and report a median personal income of USD $19,000 .{ }^{50}$ Kentucky state statistics indicate older adults are $88 \%$ white, $21 \%$ have a bachelor's degree or higher, and a mean household income of USD 58,904. ${ }^{51}$ Given these characteristics, it is difficult to know whether our findings are relevant for minorities, those with little education, or older adults with low incomes, for example. Future studies addressing knowledge of prescription drug safety should aim to include these underrepresented groups. Another limitation is that most participants reported never having experienced an interaction between alcohol and a prescription drug, even though they were unaware of potential interactions with the medications they were currently taking. This lack of awareness makes it difficult to determine whether participants would even be able to identify an alcohol and prescription drug interaction, were they to experience one. Future studies might ask participants to choose from a list of potential interactions instead of asking an open-ended question. It is also possible that changing the order of the questions could provide more accurate responses, so that participants are first asked about potential interactions with their own medications and then about which interactions they have personally experienced. Lastly, neither sample of participants (older adults or pharmacists) was randomly selected, making it difficult to know if nonresponse bias could have influenced the results. It is possible that older adults who chose not to participate were less knowledgeable about prescription drug safety, or that pharmacists who did not participate were less willing to intervene with older adults. Future studies will ideally employ a random selection of participants or utilize a larger sample of participants to reduce this potential bias. Finally, it is extremely important to note that the surveys utilized in this study require analysis of psychometric properties. For the purposes of the study objectives, with the exception of the alcohol and literacy components, the survey items were created under the assumption of face validity because no existing surveys were identified. Future research that examines psychometric properties would increase the reliability of such study findings.

In sum, the results of these two surveys show that older adults have inadequate knowledge of prescription drug safety and potential interactions with alcohol, and that pharmacists in both rural and urban settings are willing to intervene in order to raise awareness about prescription drug safety issues. Such interactions between pharmacists and older adults would likely lead to fewer medical visits as a result of fewer alcohol and prescription drug interactions requiring medical attention. Fewer medical visits would, in turn, lower the medical costs incurred by older adults misusing alcohol and prescription drugs. As such, future research should focus on 
pharmacist interventions designed to increase awareness of prescription drug safety and alcohol use in older adults.

\section{Acknowledgments}

This work was supported by grants from the National Institutes of Health awarded to TC (National Institute of Drug Abuse 5K12 DA014040), FZ (National Institute of Drug Abuse 1K01DA031764), and the Research Trust Challenge Grant awarded to the Graduate Center for Gerontology at the University of Kentucky. Special thanks also go to the University of Kentucky's College of Pharmacy, specifically Julie Kleinpeter, Molly Carr, Karen Blumenschein, Trish Rippetoe Freeman, and Holly Divine, for their insight and data collection efforts. Also, this research would not have been possible without the support of the participants.

\section{Disclosure}

The authors report no conflicts of interest in this work.

\section{References}

1. Kotecki JE. Sale of alcohol in pharmacies: results and implications of an empirical study. J Community Health. 2003;28:65-77.

2. National Institute on Alcohol Abuse and Alcoholism. Publication 27 PH 355. Jan 1995. Available from: http://pubs.niaaa.nih.gov/ publications/aa27.htm. Accessed November 29, 2012.

3. Weathermon R, Crabb DW. Alcohol and medication interactions. Alcohol Res Health. 1999;23:40-54.

4. [No authors listed]. Alcohol-related drug interactions. Pharmacist's Letter/Prescriber's Letter 2008;24(1):240106. Available from: http:// hamsnetwork.org/meds/interactions.pdf. Accessed November 29, 2012.

5. Hersh EV, Pinto A, Moore PA. Adverse drug interactions involving common prescription and over-the-counter analgesic agents. Clin Ther. 2007;29 Suppl:2477-2497.

6. Adams WL. Interactions between alcohol and other drugs. Int J Addict. 1995;30:1903-1923.

7. Brown RL, Dimond AR, Hulisz D, et al. Pharmacoepidemiology of potential alcohol-prescription drug interactions among primary care patients with alcohol-use disorders. JAm Pharm Assoc (2003). 2007;47: 135-139.

8. Zanjani F, Willis SL, Schaie KW. Alcohol consumption and cognitive change in mid to late life. Gerontologist. 2009;49 Suppl 2:471.

9. Qato DM, Alexander GC, Conti RM. Use of prescription and over-thecounter medications and dietary supplements among older adults in the United States. JAMA. 2008;300:2867-2878.

10. Aira M, Hartikainen S, Sulkava R. Community prevalence of alcohol use and concomitant use of medication - a source of possible risk in the elderly aged 75 and older? Int J Geriatr Psychiatry. 2005;20: 680-685.

11. Hayflick L. How And Why We Age. New York, NY: Ballantine Books; 1996.

12. Center for Substance Abuse Treatment. Substance abuse among older adults. Treatment Improvement Protocol (TIP) Series, Number 26. DHHS Publication No (SMA) 98-3179. Rockville, MD: Substance Abuse and Mental Health Services Administration; 1998. Available from: http://www. ncbi.nlm.nih.gov/books/NBK64419/. Accessed November 29, 2012.

13. Pringle KE, Ahern FM, Heller DA, et al. Potential for alcohol and prescription drug interactions in older people. JAm Geriatr Soc. 2005;53: 1930-1936.
14. Braithwaite RS, McGinnis KA, Conigliaro J, et al. A temporal and dose-response association between alcohol consumption and medication adherence among veterans in care. Alcohol Clin Exp Res. 2005;29: 1190-1197.

15. Adams W, Yuan Z, Barborial JJ, et al. Alcohol-related hospitalizations of elderly people. JAMA. 1993;270:1222-1225.

16. Patterson TL, Jeste DV. The potential impact of the baby-boom generation on substance abuse among elderly persons. Psychiatr Serv. 1999;50:1184-1188.

17. Ihara E, Summer L, Shirey L. Prescription drugs: a vital component of health care. In: Challenges for the 21st Century: Chronic and Disabling Conditions. Washington, DC: Center on an Aging Society, Georgetown University; 2002. Available from: http://ihcrp.georgetown.edu/ agingsociety/pdfs/rxdrugs.pdf. Accessed May 20, 2010.

18. Grossberg P, Halperin A, Mackenzie S, et al. Inside the physician's black bag: critical ingredients of brief alcohol interventions. Subst Abus. 2010;31:240-250

19. Kaner EF, Dickinson HO, Beyer F, et al. The effectiveness of brief alcohol interventions in primary care settings: a systematic review. Drug Alcohol Rev. 2009;28:301-323.

20. Tommasello AC. Substance abuse and pharmacy practice: what the community pharmacist needs to know about drug abuse and dependence. Harm Reduct J. 2004;1:3-18.

21. Schmiedt D, Ellingson J. Medication education and consultation at a senior dining program for independently living seniors. Consult Pharm. 2010;25:501-510.

22. American Society of Health-System Pharmacists. ASHP statement on the pharmacist's role in substance abuse prevention, education, and assistance. Am J Health Syst Pharm. 2003;60:1995-1998.

23. Blake SC, McMorris K, Jacobson KL, et al. A qualitative evaluation of a health literacy intervention to improve medication adherence for underserved pharmacy patients. $J$ Health Care Poor Underserved. 2010;21:559-567.

24. Siow JY, Lai PS, Chua SS, et al. The impact of pharmacist intervention on the use of activated vitamin D in a tertiary referral hospital in Malaysia. Int J Pharm Pract. 2009;17:305-311.

25. Abrons J, Vadala T, Miller S, et al. Encouraging safe medication disposal through student pharmacist intervention. $J$ Am Pharm Assoc (2003). 2010;50:169-173.

26. Jameson JP, Baty PJ. Pharmacist collaborative management of poorly controlled diabetes mellitus: a randomized controlled trial. Am J Manag Care. 2010;16:250-255.

27. McAlister FA, Majumdar SR, Padwal RS, et al. The preventing recurrent vascular events and neurological worsening through intensive organized case-management (PREVENTION) Trial protocol 2010. Available from: http://www.clinicaltrials.gov/ct2/show/NCT00931788. Accessed November 29, 2012.

28. Carter BL, Doucette WR, Franciscus CL, et al. Deterioration of blood pressure control after discontinuation of a physician-pharmacist collaborative intervention. Pharmacotherapy. 2010;30:228-235.

29. Ahmad A, Hugtenburg J, Welschen LM, et al. Effect of medication review and cognitive behaviour treatment by community pharmacists of patients discharged from the hospital on drug related problems and compliance: design of a randomized controlled trial. BMC Public Health. 2010;10:133.

30. Rothman R, Weinberger M. The role of pharmacists in clinical care: where do we go from here? Eff Clin Pract. 2002;5:91-94.

31. Partnership for Prescription Assistance. America's pharmaceutical companies stand ready to assist Kentucky residents affected by floods. Available from: http://www.pparx.org/en/news_and_media/ press_releases/2010/assist-kentucky. Accessed November 29, 2012.

32. Cain BR. The problems of prescription drug abuse. J S C Med Assoc. 1993;89:96-97.

33. Hale KM, Murawski MM, Huerta J. Pharmacist roles in combating prescription drug abuse. J Am Pharm Assoc (2003). 2009;49:589-592.

34. Kehoe WA Jr. Substance abuse: new numbers are a cause for action. Ann Pharmacother. 2008;42:270-272. 
35. Lafferty L, Hunter TS, Marsh WA. Knowledge, attitudes and practices of pharmacists concerning prescription drug abuse. J Psychoactive Drugs. 2006;38:229-232.

36. Fink A, Beck JC, Wittrock MC. Informing older adults about nonhazardous, hazardous, and harmful alcohol use. Patient Educ Couns. 2001;45:133-141.

37. Denton M, Prus S, Walters V. Gender differences in health: a Canadian study of psychosocial, structural, and behavioural determinants of health. Soc Sci Med. 2004;58:2585-2600.

38. Royak-Schaler R, Maloney PM. The process of health behavior change: individual factors and planning models. In: Sinnott JD, editor. Interdisciplinary Handbook of Adult Lifespan Learning. Westport, CT: Greenwood Press; 1994.

39. Oslin DW, Ross J, Sayers S, et al. Screening, assessment, and management of depression in VA primary care clinics: the Behavioral Health Laboratory. J Gen Intern Med. 2006;21:46-50.

40. Morris NS, MacLean CD, Chew LD, et al. The Single Item Literacy Screener: evaluation of a brief instrument to identify limited reading ability. BMC Fam Pract. 2006; 7:21.

41. Carr MB, Divine H, Hanna C, et al. Independent community pharmacis interest in participating in community pharmacy research networks. J Am Pharm Assoc (2003). 2011;51:727-733.

42. Kleinpeter J, Albrecht A, Divine H, et al. Community pharmacy research networks in the grocery store chain setting: are pharmacists willing to participate? J Am Pharm Assoc (2003). 2010;50:223.

43. Moos RH, Schutte KK, Brennan PL, et al. Older adults' alcohol consumption and late-life drinking problems: a 20-year perspective. Addiction. 2009;104:1293-1302.
44. Newsom JT, Kaplan MS, Huguet N, et al. Health behaviors in a representative sample of older Canadians: prevalences, reported change, motivation to change, and perceived barriers. Gerontologist. 2004;44:193-205.

45. Horsfield E, Sheridan J, Anderson C. What do community pharmacists think about undertaking screening and brief interventions with problem drinkers? Results of a qualitative study in New Zealand and England. Int J Pharm Pract. 2011;19:192-200.

46. Sundar RP, Becker MW, Bello NM, et al. Quantifying age-related differences in information processing behaviors when viewing prescription drug labels. PLoS One. 2012;7:e38819.

47. Slovic P, Peters E, Grana J, et al. Risk perception of prescription drugs: results of a national survey. Drug Inf J. 2007;41:81-100.

48. Administration on Aging. Department of Health and Human Services A profile of older Americans: 2011 - racial and ethnic composition. Available from: http://www.aoa.gov/AoARoot/Aging_Statistics/ Profile/2011/7.aspx. Accessed November 29, 2012.

49. Administration on Aging. Department of Health and Human Services. A profile of older Americans: 2011 - education. Available from: http://www.aoa.gov/AoARoot/Aging_Statistics/Profile/2011/13.aspx. Accessed November 29, 2012.

50. Administration on Aging. Department of Health and Human Services A profile of older Americans: 2011 - income. Available from: http:// www.aoa.gov/AoARoot/Aging_Statistics/Profile/2011/9.aspx. Accessed November 29, 2012.

51. United State Census. US Department of Commerce. American community survey. Available from: http://www.census.gov/acs/ www/about_the_survey/american_community_survey/. Accessed November 29, 2012 


\section{Supplementary materials}

\section{Prescription drug safety demographics}

Date of birth: Gender: Male/Female

Race:

- Black/African-American

- White-Caucasian

- Asian

- Native American

- Pacific Islander/Native Hawaiian

- Other

Ethnicity: Are you Spanish/Hispanic/Latino? Yes/No

County of residence: Zip code:

How many years of education have you completed?

Education: What is the highest degree that you possess?

- High school diploma/GED

- Associate's degree

- Bachelor's degree

- Master's degree

- Doctorate

Marital status

- $\quad$ Single (never married)

- Married

- Widowed

- Divorced

- Separated

- Not married, but have significant other/partner

Living arrangement: what best describes your current living arrangement? Please mark only one.

- Live alone

- Live with spouse/partner only

- Live with children/grandchildren only

- Live with spouse/partner and children/grandchildren

- Live in an institution/retirement home

- Other (please specify)

Employment: What best describes your employment status? (please mark only one)

- Employed full-time

- Employed part-time

- Unemployed, looking for work

- Unemployed, disabled

- Unemployed, volunteer

- Unemployed, retired

- Unemployed, not looking for work

- Other (please specify)

Please provide a descriptive job title:

Household income (rounded to nearest 1000): \$ , 000 


\section{Prescription drug safety assessment I}

Directions: In your opinion, how TRUE are the following statements ranging from $1=$ very true to $5=$ very false.

1. Unexpected physical and mental symptoms and interactions due to medication you are taking can be potentially dangerous and even life-threatening?

2. Alcohol consumption at any level can be harmful to you.

3. It is important to not consume more than one alcoholic drink a day.

4. It is important to talk to your doctor or pharmacist about how drinking alcohol can change the effect of medications you are taking (such as medication interactions and medication side effects).

5. Alcohol can change the effect of a medication which can result in unexpected mental and/or physical health symptoms.

6. When consuming any level of alcohol when taking a prescription medication, it is important to consider side effects seriously and talk to your doctor or pharmacist immediately about possible interactions.

7. During serious alcohol and medication interactions (unexpected physical or mental symptoms, such as slow or difficult breathing, increased heart rate, and difficulty walking or talking) it is important to visit your local emergency care clinic immediately.

\section{Prescription drug safety assessment 2}

Directions: Please answer these questions to the best of your ability.

1. Have you drank any beer, wine or liquor in the past 3 months? Yes/No.

2. How many standard drinks have you consumed each day for the past seven days?

- Monday

- Tuesday

- Wednesday

- Thursday

- Friday

- Saturday

- Sunday

3. During the past 3 months, how many times have you had 5 or more drinks in a single day? (4 or more if over the age of 64 years or female)

4. During the past 3 months, how many times have you had 3 or more drinks in a single day?

\section{Prescription drug safety assessment 3}

Directions: Please answer the following questions to the best of your ability.

1. Have you ever experienced an alcohol and prescription drug interaction such as unexpected physical and/or mental symptoms? Yes/No

- If yes, what health effects did you experience?

2. Do you talk with your doctor or pharmacist about how alcohol can interact with your prescription medication? [Five-point scale where $1=$ always and $5=$ never]

3. Do you think medications and alcohol can always be used safely together? [Five-point scale where $1=$ always and $5=$ never]

4. What do you think is a safe amount of alcohol to consume when taking prescription and nonprescription medications?

- No amount is safe

- No more than one drink a day 
- No more than 2 drinks a day

- No more than 3 drinks a day

- No more than 4 drinks a day

- No more than 5 drinks a day

- Alcohol does not need to be limited when taking medications.

5. How do you think alcohol can interact with prescription drug use and cause harmful effects (unexpected physical and mental symptoms)? Select all that apply.

- Falling

- Driving impairment

- Memory loss

- Infection

- Hospitalization

- Agitation

- Unable to perform everyday activities (eg, working, chores, and hygiene practices)

- Disability or physical or mental decline

- Conflicts with friends and family

- Loss of physical and mental orientation

- Vision loss

- Disease

- Drowsiness

- Vomiting

- Increase blood pressure

- Shortness of breath or difficulty breathing

- Death

6. What medications do you think are potentially dangerous when consuming alcohol? Select all that apply.

- Tylenol $^{\circledR}$

- Advil $^{\circledR}$

- Prescription pain treatment medications (eg, $\operatorname{Vicodin}^{\circledR}$, Percocet $\left.^{\circledR}\right)$

- Psychiatric medications for disorders such as depression/anxiety (eg, Paxil ${ }^{\circledR}$, Prozac $^{\circledR}$ )

7. Would you be willing to talk to your doctor or pharmacist about how alcohol can cause harmful prescription drug interactions (unexpected physical and mental symptoms)? [Five-point scale where $1=$ always and $5=$ never]

8. Would you be willing to change how much alcohol you consume to prevent harmful prescription drug interactions (unexpected physical and mental symptoms)? [Five-point scale where $1=$ always and $5=$ never]

9. Would you be willing to talk to friends and family about how alcohol can cause harmful prescription drug interactions (unexpected physical and mental symptoms)? [Five-point scale where $1=$ always and $5=$ never]

10. Would you be willing to be an advocate for safe alcohol and prescription drug use? [Five-point scale: 1, always to 5 , never]

11. How often do you need to have someone help you when you read instructions, pamphlets, or other written material from your doctor or pharmacy? [Five-point scale where $1=$ always and $5=$ never]

12. I can name specific drug interactions that my medication(s) can have. Yes/No

- If yes, write a specific potential drug interaction.

13. I know at least one side effect of each of my medication(s). Yes/No

- If yes, write one or more side effect of each of your medication(s).

14. I know which of my medication(s) should not be taken with alcohol. Yes/No

- If yes, write which medication(s). 
Drug, Healthcare and Patient Safety

Dovepress

\section{Publish your work in this journal}

Drug, Healthcare and Patient Safety is an international, peer-reviewed open-access journal exploring patient safety issues in the healthcare continuum from diagnostic and screening interventions through to treatment, drug therapy and surgery. The journal is characterized by the rapid reporting of reviews, original research, clinical, epidemiological and

post-marketing surveillance studies, risk management, health literacy and educational programs across all areas of healthcare delivery. The manuscript management system is completely online and includes a very quick and fair peer-review system. Visit http://www.dovepress.com/ testimonials.php to read real quotes from published authors.

Submit your manuscript here: http://www.dovepress.com/drug-healthcare-and-patient-safety-journal 